\title{
LOS RECURSOS DE NULIDAD Y UNIFICACIÓN: UN APUNTE FORAL
}

\author{
HÉCTOR HUMERES NOGUER ${ }^{*}$ \\ Universidad de Chile
}

\section{INTRODUCCIÓN}

El nuevo procedimiento laboral ha incorporado dos nuevos recursos al ámbito recursivo laboral: el de Nulidad y el de Unificación de Jurisprudencia; ello ha significado un cambio radical y muy relevante, no exento de polémica.

En efecto, durante este año, la jurisprudencia de nuestras Cortes de Apelaciones -en especial la de Santiago- ha sido variable en criterios en el de Nulidad, lo que ha evidenciado las dificultades a las que han sido enfrentados los abogados en la tramitación de estos recursos. Por otra parte, aún no ha sido posible establecer los reales alcances del de Unificación, pese a que ha aumentado significativamente el número de recursos acogidos.

A continuación, se comentarán algunos aspectos de estas temáticas.

\section{RECURSO DE NULIDAD LABORAL}

La historia de la ley nos señala que a este recurso preliminarmente se le concibió como un recurso de apelación laboral, el que, como se dejó constancia ante la Comisión del Trabajo y Seguridad Social del Senado, se concebía de una entidad muy similar a un recurso de nulidad; ello implicó que, a corto andar y por indicación del Poder Ejecutivo de la época, se modificase su tratamiento legal y se le asignase definitivamente el carácter de un recurso de derecho estricto.

Este recurso ha pasado a convertirse, por mandato del artículo 477 del Código del Trabajo en el único posible de interponer en contra de las sentencias definitivas de primera instancia.

En un concepto amplio, que incluye la naturaleza, procedencia y finalidad del recurso, debemos entender por nulidad laboral un recurso extraordinario, destinado a obtener la invalidación total o parcial del procedimiento junto con la sentencia definitiva, o solo esta última, pronụnciada por un tribunal laboral; su fundamento debe estar basado en haber sido pronunciada la sentencia o tramitado el procedimiento con infracción sustancial de los derechos y garantías constitucionales, o bien que esta se hubiere dictado con infracción de ley que hubiese influido en lo dispositivo del fallo.

En lo que respecta a su interposición, la nulidad laboral se tramita en dos fases: en primer lugar, se interpone ante el tribunal que dictó la resolución que se pretende invalidar -tribunal a quo- que será el Tribunal laboral correspondiente; y en segundo término, el re-

\footnotetext{
* Abogado. Profesor Titular, Facultad de Derecho, Universidad de Chile.
} 
curso será conocido por el tribunal superior jerárquico -tribunal ad quem-que será la Corte de Apelaciones respectiva.

Tratándose de los requisitos exigidos por el legislador para la interposición de este recurso ante el tribunal a quo, estos son: a) debe constar por escrito, b) interponerse dentro del plazo de diez días contado desde la notificación respectiva a la parte que lo entabla, c) expresar el vicio que se reclama, y d) señalar de qué modo las infracciones de los derechos y garantías constitucionales o de ley han influido sustancialmente en lo dispositivo del fallo.

Una vez interpuesto el recurso, el tribunal a quo debe pronunciarse acerca de su admisibilidad y remitir los antecedentes ante el tribunal ad quem.

Las causales de interposición del recurso se pueden agrupar en tres categorías:

I. Infracciones de derechos o garantías constitucionales, las que pueden haber tenido lugar tanto en el proceso mismo como en su fallo.

II. Infracción de ley con influencia en lo dispositivo del fallo.

III. Otras infracciones:

a) Juez incompetente, legalmente implicado o con recusación pendiente o legalmente declarada;

b) infracción manifiesta a normas de apreciación de la prueba conforme a las reglas de la sana crítica;

c) cuando sea necesario alterar la calificación jurídica de hechos, sin modificar las conclusiones fácticas del tribunal inferior;

d) cuando en el juicio se hayan violado las disposiciones sobre inmediación o de requisitos esenciales para los cuales la ley haya previsto expresamente la nulidad o los haya declarado como esencial en forma expresa;

e) cuando la sentencia se haya dictado con omisión de los requisitos establecidos en los artículos 459, 495 o 501 del Código del Trabajo o contenga decisiones contradictorias o hubiere incurrido en ultra petita;

f) cuando la sentencia hubiere sido dictada contra autoridad de cosa juzgada, alegada oportunamente.

El tribunal a quo deberá pronunciarse sobre la admisibilidad del recurso en relación a los requisitos, formales si estima que se ellos se cumplen, deberá enviar los antecedentes a la Corte respectiva dentro de tercero día de notificada la resolución que concede el último recurso, suspendiéndose los efectos de la sentencia recurrida.

La Corte de Apelaciones al conocer el recurso, a su vez, debe pronunciarse en cuenta acerca de la admisibilidad. Al practicar este examen, el tribunal ad quem debe verificar:

a) El cumplimiento de los requisitos del inciso 1 del artículo 479 C.T.

b) Si tiene fundamentos de hecho o de derecho.

c) Si tiene peticiones concretas.

d) Si se ha preparado en forma oportuna. 
Asimismo, la vista de la causa de este recurso, se encuentra revestida de ciertas características específicas:

i) no existe relación -formal al menos-

ii) Los alegatos pueden tener lugar por un máximo de 30 minutos,

iii) no. se rinde prueba, salvo para probar la causal alegada.

En los trámites posteriores a la vista de la causa, la Corte de Apelaciones debe dictar el fallo dentro de $5^{\circ}$ día. Si se acoge el recurso por las causales de las letras b), c), e) y f) del artículo 478 del Código del Trabajo, se debe dictar sentencia de reemplazo; en los demás casos solo se determina el estado del proceso; además, la Corte puede corregir errores que no influyan en la parte dispositiva del fallo.

Cabe hacer notar que en caso de acogerse el recurso de Nulidad, no procede recurso alguno en contra de la nueva sentencia que se emita en el nuevo juicio que deba realizarse. Cabe acotar que en el año 2010, hasta el mes de septiembre, se habían presentado en las 17 Cortes de Apelaciones del país un total de 3.153 ingresos por recursos de Nulidad, tal como se acredita en las siguientes tablas y gráficos:

\begin{tabular}{lc}
\hline \multicolumn{1}{c}{ Corte } & Rec. Nulidad (Ref. Laboral) Ingresados \\
\hline C.A. de Arica & 29 \\
C.A. de Iquique & 64 \\
C.A. de Antofagasta & 155 \\
C.A. de Copiapó & 46 \\
C.A. de La Serena & 119 \\
C.A. de Valparaíso & $\mathbf{3 8 0}$ \\
C.A. de Rancagua & 137 \\
C.A. de Talca & 155 \\
C.A. de Chillan & 39 \\
C.A. de Concepción & $\mathbf{2 1 8}$ \\
C.A. de Temuco & 119 \\
C.A. de Valdivia & 148 \\
C.A. de Puerto Montt & 157 \\
C.A. de Coyhaique & 14 \\
C.A. de Punta Arenas & 27 \\
C.A. de Santiago & $\mathbf{1 . 0 7 9}$ \\
C.A. de San Miguel & 267 \\
Total general & 3.153 \\
\hline
\end{tabular}




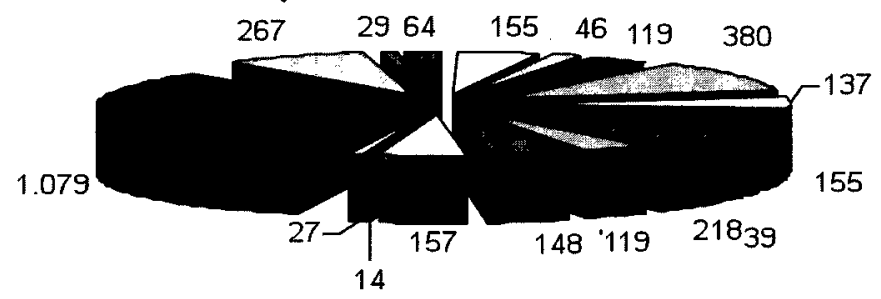

\begin{tabular}{|lll|}
\hline $\mathbf{a}$ C.A. DEARICA & $\square$ C.A. DE IQUIQUE & $\square$ C.A. DE ANTOFAGASTA \\
$\square$ C.A. DE COPIAPO & C.A. DE LA SERENA & $\square$ C.A. DE VALPARAISO \\
$\square$ C.A. DE RANCAGUA & $\square$ C.A. DE TALCA & $\square$ C.A. DE CHILLAN \\
C.A. DE CONCEPCION & $\square$ C.A. DE TEMUCO & C.A. DE VALDIVIA \\
$\square$ C.A. DE PUERTO MONTT & $\square$ C.A. DE COYHAIQUE & $\square$ C.A. DE PUNTA.ARENAS \\
C.A. DE SANTIAGO & $\square$ C.A. DE SAN MIGUEL & \\
\hline
\end{tabular}

Fuente: Elaboración propia, a través de datos obtenidos en el sitio Web del Poder Judicial

Es del caso recordar que en la Región Metropolitana, la reforma procesal laboral comenzó a regir desde agosto de 2009. Como veremos, durante los meses de octubre a diciembre de 2009 la situación de los recursos de Nulidad en la Corte de Apelaciones de Santiago inicialmente no cabía estimarla como crítica, según puede apreciarse la relación entre admisibilidades e inadmisibilidades, tal como se grafica en la lámina inserta a continuación:

\section{Nulidad octubre - diciembre 2009}

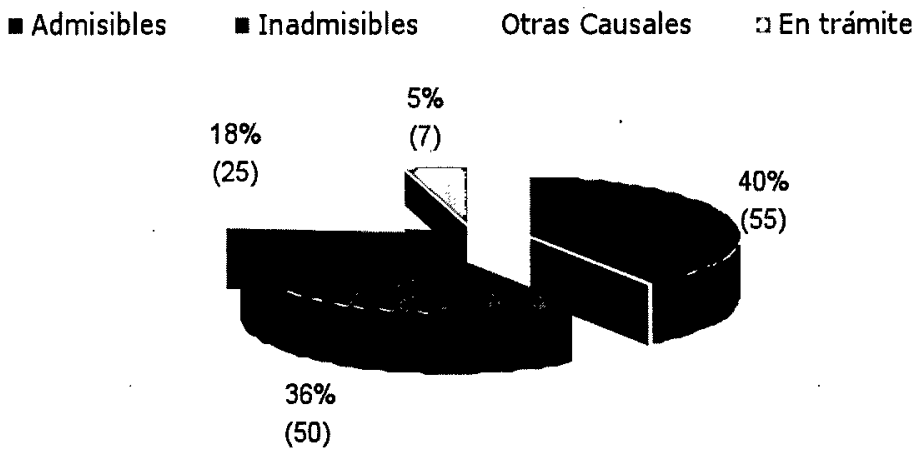

Fuente: Elaboración propia, a través de datos obtenidos en el sitio Web del Poder Judicial

Pero dicha situación tuvo un giro radical a contar del mes de marzo del año 2010, al ingresarse un total de 356 recursos, de los cuales 207 -que corresponden al 59\%-, fueron declarados inadmisibles; de los declarados admisibles, 68 fueron declarados rechazados (19\%) y 12 acogidos (3\%). Lo expuesto es posible visualizarlo en el siguiente gráfico: 


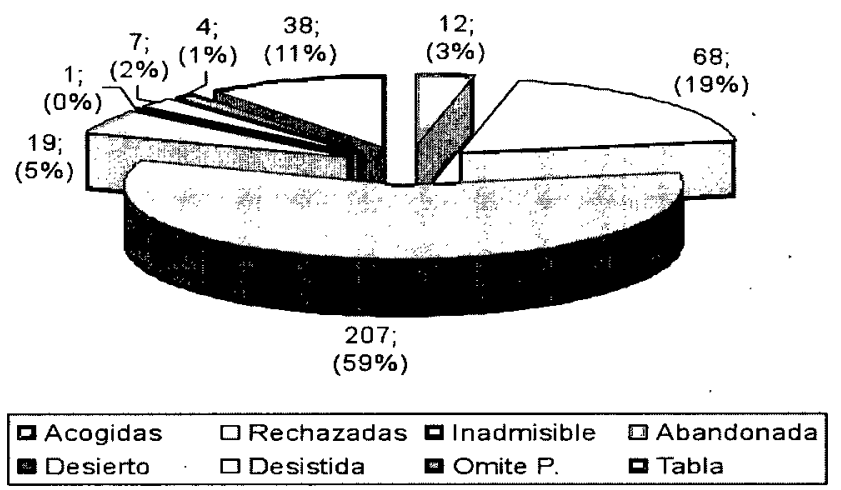

Fuente: Elaboración propia, a través de datos obtenidos en el sitio Web del Poder Judicial

Asimismo, en cuanto a las causales invocadas, la admisibilidad da cuenta del rechazo de alrededor de un $73 \%$ por las señaladas en el artículo 477 del Código del Trabajo, siendo el porcentaje restante, por aplicación de las causales señaladas en el artículo 478 del Código del Trabajo.

También es apreciable que los recursos de Nulidad definitivamente acogidos, no superaron el 3\% de los ingresados, lo que de por sí solo denota el poco éxito que su interposición estaba teniendo.

En la práctica de la Corte de Apelaciones de Santiago, en el período del año 2010, fue posible verificar que las causales más usuales que motivaron la declaración de inadmisibilidad de los recursos de Nulidad, se encontraban vinculadas a los siguientes aspectos:

a) Falta de fundamentos de hecho y de derecho

- Se han denunciado simultáneamente infracciones de ley e impugnación de la valoración de la prueba.

- No se ha expuesto la forma en que se ha producido la vulneración de las normas invocadas.

- No se ha expuesto la forma de vulneración de la apreciación sana crítica.

- La causal invocada no condice con los hechos de la causa.

- Se ha denunciado infracción de ley, pero sin especificar cómo se produce ni en qué consiste.

- La causal invocada no resulta ajustada al mérito del proceso.

b) Falta de peticiones concretas

- Solo se pide que se declare justificado el despido.

- $\quad$ Solo se pide dictación de sentencia de reemplazo.

- Solo se pide anulación de fallo.

- Las peticiones no se ajustan a la causal invocada.

c) Pluralidad de causales: No se indica si las causales se interponen en forma conjunta o subsidiaria -recurso de derecho estricto-. 
Lo anteriormente expuesto estaría avalando la posición sustentada en la Corte en cuanto que existiría cierta desprolijidad por parte de los abogados en la correcta determinación del recurso, pero también ha de considerarse que varias de las causales de rechazo expuestas se refieren al fondo del recurso y no a su forma, aspecto no menor y que incidió fuertemente en las declaraciones de inadmisibilidad, tal como se apreciará en el comentario que sigue.

Dado que este recurso reviste una gran relevancia y constituye el único medio de impugnación de parte en primera instancia, no es menor que estas cifras y causales de rechazo provocaren una justificada alarma entre los abogados a cargo de los respectivos recursos, contra cuyo fallo no procede recurso alguno, salvo que se den las condiciones relativas a un recurso de Unificación. Por ende, enfrentados los letrados a esa circunstancia tan crucial, una gran cantidad de ellos recurrieron al antiguo recurso de queja, el que comenzó a incrementar exponencialmente su número contar del mes de marzo del año 2010.

La situación antes descrita fue conocida por esta vía por la Cuarta Sala de la Corte Suprema, la que a contar del 22 de abril de 2010, emitió sendos fallos resolviendo recursos de queja relativos a la inadmisibilidad del Recurso de Nulidad resueltos por la Sala Tramitadora de la Corte de Apelaciones de Santiago -Primera Sala-; al respecto, cabe destacar que desechó un porcentaje muy alto de las Quejas interpuestas $-97 \%$ - ya fuere estimándolas inadmisible o bien rechazándolas directamente, pero actuando de oficio, y fundada en el artículo $84 \mathrm{CPC}$, decretó la admisibilidad de los recursos de Nulidad respectivos y ordenó que estos fueren conocidos por las Corte de Apelaciones referida.

El siguiente gráfico nos entrega información sobre el recurso de queja laboral -enerooctubre 2010-:

\section{Acogido Dechazado $\square$ Inadmisible}

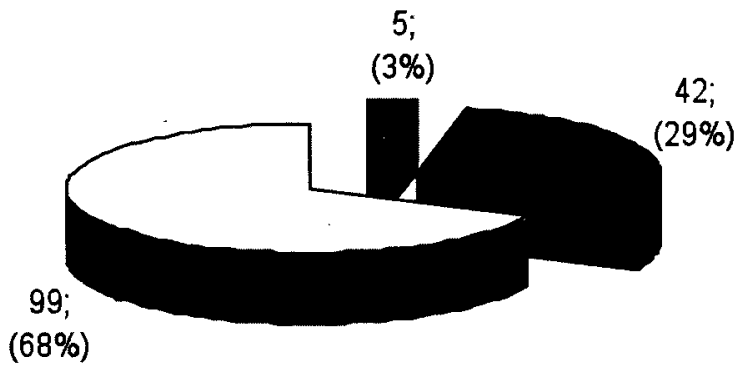

Fuente: Elaboración propia, a través de datos obtenidos en el sitio Web del Poder Judicial

La Cuarta Sala de la Corte Suprema estableció un criterio para ordenar la admisibilidad referida, la que puede sintetizarse en la forma siguiente: 
a) A la Iltma. Corte de Apelaciones no le corresponde ponderar la calidad de los fundamentos del recurso, sino su existencia o inexistencia;

b) La Iltma. Corte Apelaciones ha interpretado de manera distinta que la señalada en la ley, condición procesal que implica imponer requisitos más allá de la normativa que rige la materia; $o$

c) La Iltma. Corte Apelaciones debe revisar los requisitos de admisibilidad comprendiendo entre otras, la determinación, existencia o inexistencia de fundamentos de hecho o derecho, la que en caso alguno abarca su desacierto, ineficacia o insuficiencia.

A partir del establecimiento de dicha doctrina, la controversia sobre el recurso de nulidad laboral adoptó un camino diferente, ya que la Corte de Apelaciones de Santiago procedió a resolver de allí en adelante las inadmisibilidades de la siguiente manera:

"Atendida la jurisprudencia de la Excma. Corte Suprema, al momento de dar cuenta de la admisibilidad de un recurso de nulidad interpuesto en contra de una sentencia definitiva en materia laboral, solo corresponde examinar y revisar los requisitos aludidos en el artículo 480 del Código del Trabajo, esto es, de aquellos referidos en el inciso 1 del artículo 479 del mencionado cuerpo legal, cuales son, que el recurso haya sido interpuesto por escrito, ante el tribunal que dictó la resolución que se impugna y dentro del plazo establecido; como también los referidos en el último inciso del artículo 480 del Código del Trabajo, esto es, si contiene fundamentos de hecho o de derecho o peticiones concretas, y en los casos que corresponda que este haya sido preparado oportunamente, requisito que contiene el recurso que da origen a la alzada, razón por la cual se declara admisible el recurso de nulidad interpuesto por la parte demandante, contra la sentencia de fecha veinticuatro de septiembre de dos mil diez, dictada por el Primer Juzgado de Letras del Trabajo de Santiago. Pasen los antecedentes al señor Presidente, para su inclusión en la tabla ordinaria que corresponda"'.

Con ello se zanjó un tema de por sí controversial, pero que vino a solucionar un agudo problema que se había suscitado en relación a la declaración de inadmisibilidad del recurso de Nulidad, de un modo coherente con las restantes 16 Cortes de Apelaciones del país, como es dable apreciar en el gráfico siguiente:

1 Corte de Apelaciones de Santiago, 25 de octubre de 2010. No Ingreso 1415-2010. 


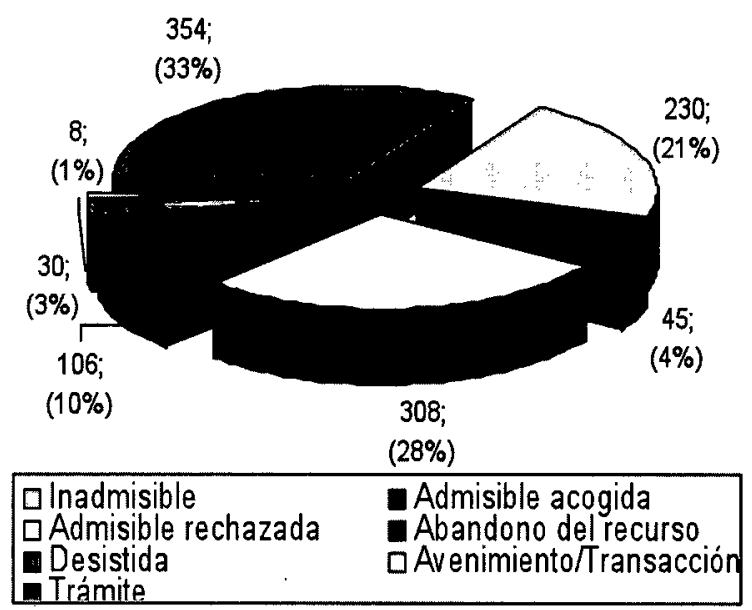

Fuente: Elaboración propia, a través de datos obtenidos en el sitio Web del Poder Judicial

En todo caso, debe anotarse que el éxito definitivo de los recursos de Nulidad no ha tenido un cambio significativo, ya que solo un $4 \%$ de los mismos han resultado acogidos en definitiva. Ello hace concluir que, en la práctica, el juicio laboral se reduce a la primera instancia, pensamiento que no estuvo ajeno al quehacer del Foro Laboral que dio origen al nuevo procedimiento oral; pero cabe recodar que cuando ello se planteó, se tuvo en vista la existencia de Tribunales colegiados. Ese tema se encuentra aún pendiente de discusión, aun cuando ya se han escuchado opiniones de abogados, académicos y parlamentarios, instando por su instauración. De igual modo, se han planteado algunas iniciativas tendientes al reemplazo del recurso de Nulidad, las que debieran guardar la coherencia del sistema recursivo laboral.

\section{RECURSO DE UNIFICACIÓN DE JURISPRUDENCIA}

Este recurso, según se señaló durante la tramitación en el Congreso de la ley № 20.260, tiene por finalidad obtener una interpretación uniforme de la Corte Suprema para que esta, en definitiva, fije el sentido de las normas laborales, la circunstancia habilitante para acceder a esa sede superior es precisamente la existencia de pronunciamientos contradictorios en la jurisprudencia.

El recurso de Unificación de Jurisprudencia es de carácter extraordinario y de derecho, conocido por la Corte Suprema, y solo procede contra la resolución que falle el recurso de Nulidad, pronunciada por la respectiva Corte de Apelaciones, basado en la única causal de que respecto de una misma materia de derecho, objeto del juicio, existieren diversas interpretaciones sostenidas en un o más fallos firmes emanados de los Tribunales Superiores de Justicia.

Por lo tanto, los requisitos para su procedencia son: 
a) Que la resolución recurrida sea una sentencia que falle un recurso de nulidad,

b) Que respecto de la materia de derecho objeto del juicio existieren distintas interpretaciones,

c) Que las diferentes interpretaciones hayan sido sostenidas en uno o más fallos firmes de Tribunales Superiores de Justicia,

d) Que se interponga ante la Corte de Apelaciones respectiva,

e) Que se interponga en el plazo de 15 días desde la notificación de la sentencia que se recurre.

La tramitación del recurso comprende dos etapas:

1) Ante el tribunal a quo. El tribunal deberá apreciar la admisibilidad, pronunciándose de plano sobre la fianza de resultas, si se solicita, y remitir los autos al tribunal ad quem.

2) Ante el Tribunal ad quem: La Corte Suprema deberá realizar el examen de admisibilidad según el artículo 483-A del Código del Trabajo. Una vez declarado admisible el recurso, para la vista de la causa deben observarse las mismas reglas establecidas para las Apelaciones (C.P.C), limitando la duración de las alegaciones de cada parte a 30 minutos. Terminada la audiencia, el Tribunal debe fallar si acoge el recurso, y dictar acto continuo y sin nueva vista, la sentencia de reemplazo en Unificación de Jurisprudencia.

Desde la entrada en vigencia de la reforma laboral en la Región Metropolitana -30 de agosto de 2009-, se han presentado 296 recursos de Unificación. De este número, 222, los que equivalen al $75 \%$, han sido declarados inadmisibles, por no presentados, desiertos y desistidos. Es más, de los recurso declarados admisibles, solo $48-16 \%$ - han sido acogidos.

El siguiente gráfico muestra la situación comentada:

Inad/ otros Rechazados Ocogidos

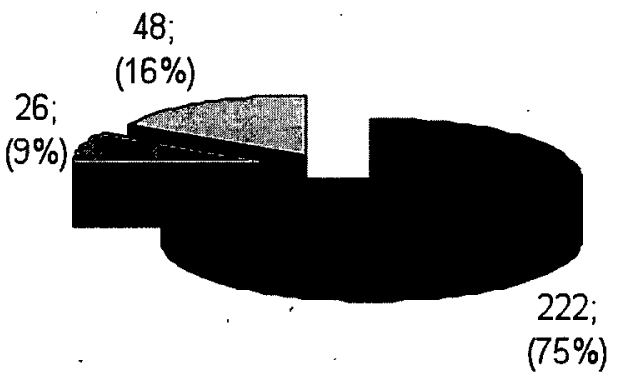

Fuente: Elaboración propia, a través de datos obtenidos en el sitio Web del Poder Judicial. 
Las materias que han sido objeto de Unificación por la Corte Suprema corresponden a las siguientes:

- Causal de plazo fijo en contratos de plazo indefinidó (1)

- Validez del finiquito (1)

- Contratos a honorarios y vínculo laboral (1)

- Aplicación ley laboral a funcionarios Municipales (1)

- $\quad$ Representación del empleador (1)

- Supremacía Ley de Quiebras sobre casual de término de contrato (1)

- $\quad$ Pago de indemnización adicional (1)

- $\quad$ Aplicación prioritaria de Código del Trabajo (1)

- Nulidad de despido por falta de pago de cotizaciones previsionales (2)

- Carácter declarativo de sentencia que reconoce vínculo laboral (1)

- Indemnización no comprende asignaciones de colación y movilización (2)

- Aplicación de indemnización contenida en el artículo 2 transitorio ley No 19070 en caso de renuncia voluntaria del docente en establecimiento educacional municipal (31)

- Desafuero trabajador municipal (1)

- Aplicación de causal No 5 del artículo 159 del Código del Trabajo (1)

- Desafuero sindical (1)

- $\quad$ Anulación de Oficio (1) ${ }^{2}$

Lo anterior indica que la función del recurso de unificación no ha tenido el decurso esperado, ya que los criterios unificados por la Corte Suprema, no han representado innovaciones -salvo algunos casos-, ya que en su gran mayoría corresponden a criterios que habían sido establecidos con anterioridad por medio de los recursos de Casación en la Forma y en el Fondo, correspondientes al antiguo procedimiento o bien se han centrado fuertemente en materias unívocas, como es el caso de la aplicación de indemnización contenida en el artículo $2^{\circ}$ transitorio ley No 19070 en caso de renuncia voluntaria del docente en establecimiento educacional, sobre la que hay 31 fallos.

Resulta evidente, pues, que el recurso de Unificación en el nuevo sistema procesal, es insuficiente para establecer la luz de establecer una doctrina que oriente y guíe la jurisprudencia laboral nacional, a más de ser tributario de varias deficiencias técnicas y conceptuales.

$\mathrm{Al}$ respecto, el Proyecto de ley sobre reforma del Código de Procedimiento Civil, el cual establece en sus artículos 353 y siguientes, la creación de un denominado Recurso Extraordinario, que procederá cuando:

a) La sentencia recurrida se oponga a la jurisprudencia uniforme.

b) La jurisprudencia previa fuere contradictoria entre sí.

c) No existiere jurisprudencia sobre la materia.

2 Los números indican la cantidad de fallos por criterios. 
d) Existieren nuevos contextos históricos, sociales o culturales justifiquen variar la tendencia jurisprudencial.

Nos parece que este recurso se ajusta con mucho mayor acierto al rol que efectivamente debiera esperarse le corresponde a la Sala Laboral de la Corte Suprema.

Creemos del caso analizar la posibilidad de reformular este régimen y crear las condiciones adecuadas para que el rol de la Corte Suprema en esta materia adquiera la relevancia que el mundo jurídico laboral anhela, generando una doctrina realmente orientadora sobre la materia, la que mucho necesita un derecho sometido a constantes cambios y adaptaciones. Subsanar la falta de una seguridad jurídica derivada de un criterio judicial conocido creemos cooperaría poderosamente con el establecimiento de la ansiada paz social. 